Revista Aspas

ppgac - USP

Especial

\title{
CORPOS KÕKAMÕU: UMA RELAÇÃO SIMÉTRICA ENTRE INDÍGENA E NÃO INDÍGENA NA TRÍADE CORPO-CULTURA-ALDEIA/CIDADE
}

\section{KÖKAMÕU BODIES: A SYMMETRICAL RELATIONSHIP BETWEEN INDIGENOUS AND NON-INDIGENOUS IN THE BODY-CULTURE-VILLAGE / CITY TRIAD}

CUERPOS KÕKAMÕU: UNA RELACIÓN SIMÉTRICA ENTRE INDÍGENAS Y NO INDÍGENAS EN LA TRÍADA CUERPO-CULTURA-PUEBLO / CIUDAD

\section{Luiz Davi Vieira Gonçalves}

Luiz Davi Vieira Gonçalves

Professor Adjunto da Universidade do Estado do Amazonas

(UEA), Curso de Teatro. Doutor e pós-doutorando em Antropologia Social pela Universidade Federal do Amazonas (UFAM). Líder do diretório de pesquisa: TABIHUNI/CNPq/UEA e Pesquisador do Instituto Nacional de Ciência e Tecnologia Brasil

Plural (INCT). E-mail: luizdavipesquisa@hotmail.com 


\section{Resumo}

Este artigo apresenta uma reflexão sobre os afetos construídos na relação kõkamõu - juntos(as) -, entre indígenas e não indígenas na tríade, corpocultura-aldeia/cidade. Um olhar simétrico para o corpo e cultura Yanonami da Região de Maturacá, Alto Rio Negro (Amazonas), transmutando as barreiras preestabelecidas do campo da pesquisa científica, o que previa um distanciamento para análise.

Palavras-chaves: Yanonami, kõkamõu, corpo, cidade-aldeia.

\section{Abstract}

This article presents a reflection on the affections constructed in the kõkamõu relationship - together -, between indigenous and nonindigenous in the triad, body-culture-village/city. A symmetrical look at the Yanonami body and culture of the Maturacá Region, Alto Rio Negro (Amazonas), transmuting the pre-established barriers in the field of scientific research that precedes a distance for analysis.

Keywords: Yanomami, kõkamõu, body, city-village.

\section{Resumen}

Este artículo presenta una reflexión sobre los afectos construidos en la relación kõkamõu, juntos, entre pueblos indígenas y no indígenas en la tríada, cuerpo-cultura-pueblo / ciudad. Una mirada simétrica al cuerpo y la cultura yanonami de la región de Maturacá, Alto Río Negro (Amazonas), transmutando las barreras preestablecidas en el campo de la investigación científica, lo que proporcionó una distancia para el análisis.

Palabras clave: Yanonami, kõkamõu, cuerpo, pueblo-pueblo.

O campo das artes cênicas no Brasil vem, nos últimos anos, demonstrando um grande interesse nas práticas culturais dos povos tradicionais, haja vista o aumento de pesquisas apresentadas nos principais eventos científicos como os Congressos e Encontros da Associação Brasileira de Pesquisa e Pós-Graduação em Artes Cênicas (ABRACE) e o Congresso Nacional da Federação de Arte/Educadores do Brasil (CONFAEB). 
Notadamente, esse aumento ocorre pelo interesse no distanciamento das práticas e teorias europeias, corroborando com o que Walter Mignolo chama de gesto decolonial:

\begin{abstract}
gestos decoloniais seriam quaisquer e todos os gestos que direta ou indiretamente se engajam na desobediência dos ditames da matriz colonial e contribuem para a construção da espécie humana no planeta em harmonia com a vida no/do planeta, da qual a espécie humana é apenas uma ínfima parte e da qual depende. E isso contribuiu para a re-emergência, res-surgência e re-existência planetária de pessoas cujos valores, modos de ser, línguas, pensamentos e histórias foram degradados para serem dominados. (MIGNOLO apud ICLE; HAAS, 2019, p. 98).
\end{abstract}

Todavia, a relação das artes cênicas com os povos tradicionais, em alguns casos, pode causar o que a pesquisadora Patrice Pavis (2010, p. 144) chama de pornografia etnográfica: "os falsos rituais fazem perder a consciência do funcionamento de nosso mundo. A busca de autenticidade não é mais do que um fantasma ocidental para representar as outras pessoas, uma espécie de pornografia etnográfica". Com certeza, o perigo da pornografia etnográfica é o estereótipo da cultura tradicional. Uma armadilha intercultural:

\begin{abstract}
Caso se examinem as inumeráveis práticas espetaculares - e em especial aquelas que antigamente chamavam-se tradições teatrais -, podem-se distinguir nelas elementos rituais próprios a cada contexto cultural. Na falta de conhecimentos antropológicos e linguísticos suficientes, os pesquisadores têm a tendência de reconduzir tudo a essas cerimônias e formas rituais. [...] Haverá de parecer estranho estudar o papel dos rituais nas produções teatrais e nas performances contemporâneas, visto que não se imagina que o ritual possa estar a serviço do teatro. Entretanto, depois de quarenta anos, inúmeros espetáculos inspiram-se em rituais existentes ou, ainda mais frequentemente, inventam ou parodiam os seus próprios rituais. Isso é um signo de maturidade? (PAVIS, 2010, p. 135)
\end{abstract}

Neste mesmo sentido relatado por Patrice Pavis na citação anterior, analisei no artigo Estudos Étnicos no Teatro: a metodologia Kõkamõu como perspectiva simétrica para o processo de pesquisa e criação em arte (2018a), publicado na revista Arte da Cena, o perigo dessas armadilhas interculturais e das pornografias etnográficas para os povos indígenas nos tempos atuais. Trouxe aos alfarrábios do artigo minha experiência na Amazônia trabalhando 
como artista-antropólogo em contexto dos povos demarcados como os Yanonami ${ }^{+}$Kubeo e Ye'pá Mahsã, além, também, do trabalho com os povos indígenas em contexto urbano, atuando com indígenas de quase trinta etnias presentes na cidade de Manaus. Ou seja, de um lado, estou inserido em uma realidade em que, no dia a dia, compartilho as dificuldades, os desafios e a luta dos indígenas para sobreviverem e, do outro, ainda encontro grupos de teatro e artistas vindo na Amazônia tirar foto, realizar pesquisas de rituais, práticas culturais e irem embora deixando o indígena sem nenhum respaldo do que foi feito e será feito com o material "coletado".

Por conseguinte, visando contribuir para o teatro decolonial, mas preocupado com as armadilhas interculturais nas relações entre artistas e povos indígenas, venho sugerir, com base nas experiências na Amazônia e, principalmente, na minha relação com os Yanonami de Maturacá, a metodologia kõkamõu que, na língua Yanonami, significa juntos(as), propondo assim uma relação afetiva simétrica entre indígena e não indígena (GONÇALVES, 2018:2019). Tendo em vista isso, para este artigo, trago uma análise de um dos frutos da metodologia kõkamõu com os Yanonami: a tríade, corpo-cultura-aldeia/cidade. Neste artigo, é importante tomar como base a seguinte reflexão: como, nos tempos atuais, podemos desenvolver uma relação simétrica entre artista e povos tradicionais?

\section{A tríade, corpo-cultura-aldeia/cidade}

Não foi você que veio até nós, foram os espíritos que trouxeram você para ajudar o povo Yanonami. Cacique Antonio Lopes - Aldeia Maturacá

O campo mudou a minha vida (GONÇALVES, 2018a, p. 25). Eis-me aqui após ser afetado pelo xamanismo - hekuramou, Yanonami da aldeia Maturacá! Um artista que se tornou antropólogo, que depois se (re)conheceu

\footnotetext{
${ }^{1}$ Usarei o termo Yanonami (com " $n$ " e “i”) todas as vezes que me referir ao subgrupo linguístico com o qual estou trabalhando, pois assim se denominam. Usarei, por sua vez, o termo Yanomami (com " $m$ " e "i") para se referir ao conjunto cultural e linguístico mais amplo, composto por vários subgrupos, conforme apresento na tese de doutorado: $O(s)$ Corpo $(s)$ Kõkamõu: A performatividade do pajé-hekura Yanonami da região de Maturacá. Disponível em: https://tede.ufam.edu.br/handle/tede/7109
} 
como artista e, em seguida, no exercício juntos(as) - kõkamõu -, com povo Yanonami, aprendeu a ser artista-antropólogo. Inserido no contexto que, inicialmente, previa apenas entender e/ou conhecer a prática corporal em um modelo de ritual indígena para realização de uma pesquisa acadêmica, não imaginava que a afetação chegasse ao nível de transformar minha prática como professor de teatro, como diretor de teatro, como performer, como pai, como filho, sobretudo, como ser humano.

$O$ afeto com os Yanonami inicia-se ainda no ano de 2014 quando ainda estava realizando o levantamento bibliográfico para o desenvolvimento do projeto de doutorado, no entanto, desde essa data até os tempos atuais, mantemos contato, via e-mails, WhatsApp e encontros presenciais na aldeia de Maturacá e na minha casa em Manaus (GONÇALVES, 2019).

Maturacá é uma das regiões da Terra Indígena Yanomami. Ela está situada no Alto Rio Negro e é banhada pelos rios Maturacá e Ariabú, os quais, com suas águas escuras, após alguns quilômetros, misturam-se com as águas claras do Rio Cauaburis, chamado na língua Yanomami de Paretota, que significa "muito mosquito", uma referência à quantidade de inseto ali encontrado.

O Cauaburis nasce nas montanhas da fronteira do Brasil com a Venezuela, região conhecida popularmente como "Cabeça do Cachorro", e quase toda sua extensão está dentro do território Yanonami. Assim, a cartografia da região de Maturacá é composta por cinco xaponos (aldeias), à beira do Rio Maturacá e Ariabú, são eles: xapono Ariabú, xapono Maturacá, xapono União, xapono Maria Auxiliadora e xapono Santa Maria. Além deles, há mais quatro xaponos, Maiá, Inanbú, Aiarí e Nazaré, distribuídos às margens do Rio Cauaburis e seus afluentes.

Recebê-los em meu yano (casa) em Manaus é, a priori, desafiador, pois, em alguns casos, só conversávamos na língua nativa, sem falar que o ritmo da casa muda completamente quando eles chegam, tornando-se um xapono; fazendo com que tudo aquilo que eu buscava na aldeia viesse para dentro de minha casa, para dentro de mim. No entanto, normalmente os motivos pelos quais fazem com que eles saíam de seus xaponos estão ligados às relações interétnicas e, por isso, poder contar com alguém de confiança 
que conhece a realidade de seu povo é, segundo a liderança Yanonami, de suma importância, Portanto, estar kõkamõu significa também caminhar junto no(s) processo(s) de diálogo(s) com o mundo dos napë (brancos). Vale salientar que as vozes dos indígenas e não indígenas são fortalecidas estando kõkamõu, independentemente do local e da qualidade de presença.

Neste sentido, destaco, entre muitas atividades desenvolvidas, a realização, em 2017, do evento Suwë pë Kõkamõu: arte, cultura e articulações de mulheres indígenas; a participação, em 2018, na IX Reunião Científica da Associação Brasileira de Pesquisa e Pós-Graduação em Artes Cênicas ABRACE; também nesse mesmo ano, a escrita do livro $O$ Xamanismo Yanonami da Região de Maturacá/Yanonami të pë hekuramou Maturacá a xapono há; em 2019, a construção da casa de apoio na frente sul de São Gabriel da Cachoeira e, no contexto da pandemia do Covid-19, a elaboração da Nota Técnica para Contribuir ao Combate da Covid-19 na Terra Indígena Yanomami (RAMOS, et al., 2020), além de minhas idas, uma ou duas vezes por ano, à região de Maturacá.

O evento Suwë pë Kõkamõu ocorreu entre os dias 4 e 8 de abril de 2017 e reuniu, na cidade de Manaus, doze mulheres Yanonami da região de Maturacá para apresentarem aos napë a recém-criada Associação de Mulheres Yanonami (AMY-Kumirãyõma), além de exporem seus artesanatos e dialogarem com outras lideranças femininas da Amazônia sobre os diferentes contextos da economia e política indígena voltada para as organizações das mulheres indígenas. A associação AMY-Kumirãyõma conseguiu articular uma rede de instituições apoiadoras que arcaram com os custos da viagem de dessas doze mulheres para Manaus.

O evento também contou com a participação da professora da Universidade Estadual de Campinas (Unicamp), Dra Verônica Fabrini, e da mestranda em Teatro, pela mesma Universidade, Arami Marschner, como convidadas, complementando a programação do evento. Elas trouxeram oficinas e palestras que fomentaram a importância do conhecimento indígena nas Artes da Cena, sobretudo no campo de pesquisa acadêmica teatral. $O$ evento, com a distribuição das atividades, buscou relacionar o campo 
antropológico e teatral, conquistando a participação dos pesquisadores em Antropologia e dos pesquisadores das Artes da Cena.

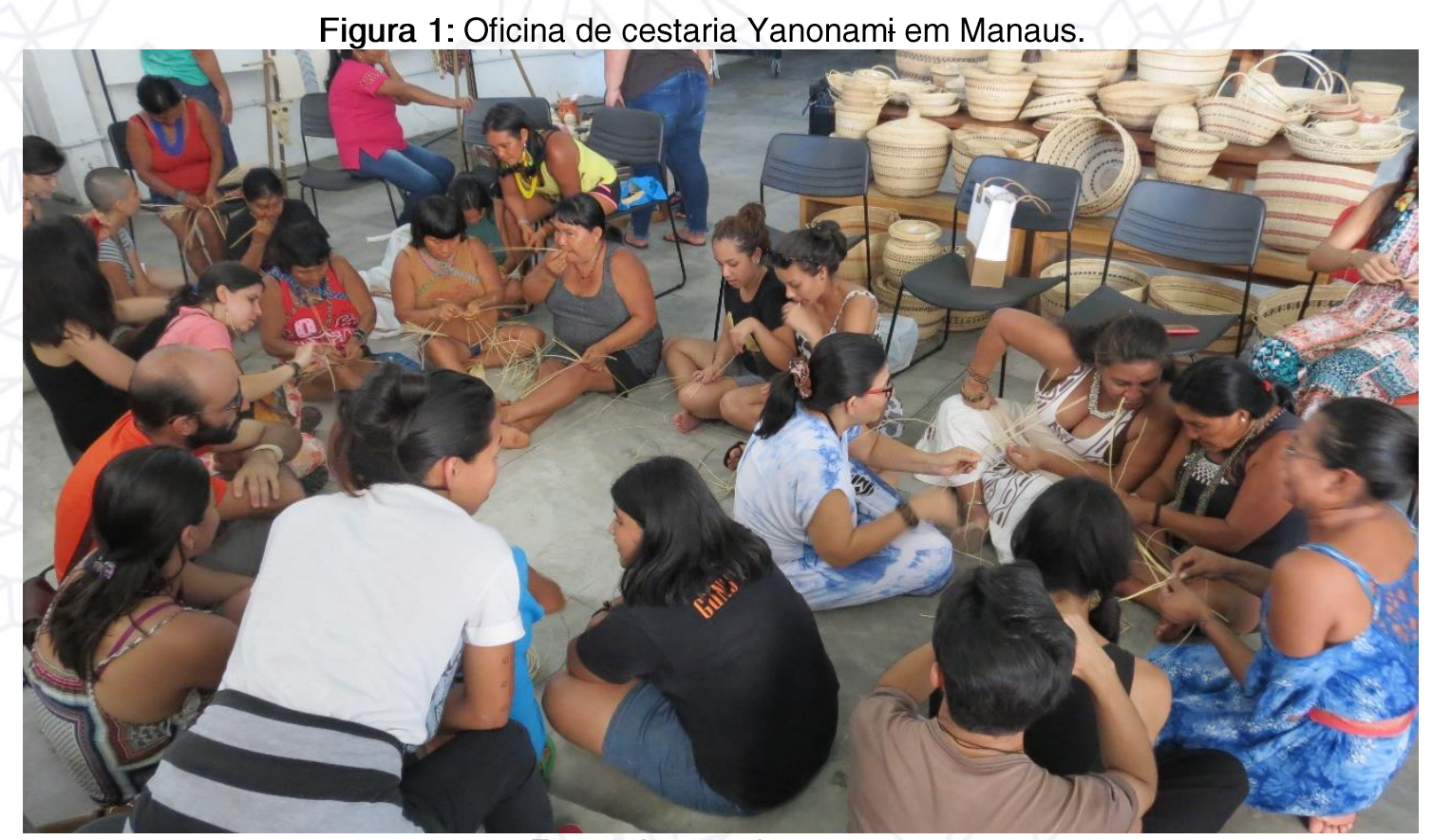

Fonte: Acervo do autor.

Após o evento Suwë pë Kõkamõu, em meados do mês de junho, recebi o convite para participar da IX Reunião Científica da Associação Brasileira de Pesquisa e Pós-Graduação (ABRACE, 2017), através do presidente da Associação Dr. Robson Carlos Haderchpek, que representava a comissão organizadora. O objetivo era contemplar o tema do evento: Diversidade de Saberes: as Artes Cênicas em diálogo com o Mundo, que, neste caso, seria representado pelo conhecimento indígena, ou seja, o convite se estendia aos Yanonami, já que a comissão organizadora tinha ciência de minha pesquisa de doutorado apresentada em Grupos de Trabalhos do próprio evento em edições anteriores.

Logo, estendi o contato ao povo de Maturacá contatando a Associação Yanomami do Rio Cauaburis e Adjacentes (AYRCA) e suas lideranças tradicionais. $O$ convite foi aceito pela liderança Yanonami com a finalidade de divulgar e fortalecer a AYRCA, além de obter reconhecimento acerca dos conhecimentos tradicionais do povo de Maturacá enquanto conhecimentos legítimos Yanomami, já que, quando se ouve falar em Yanomami, a primeira 
lembrança é sobre os grupos do Estado de Roraima e, principalmente, sobre Davi Kopenawa.

O evento aconteceu no período de 27 a 30 de setembro de 2017, na cidade de Natal (RN). Como representantes de Maturacá, participaram da ABRACE/2017 dois Yanonami: o pajé-hekura Carlos Machado e o professor Marcos Figueiredo, vice-presidente da Associação Yanomami do Rio Cauaburis e Adjacentes (AYRCA).

Os dois Yanonami, professor Marcos Figueiredo e o pajé-hekura Carlos Machado, apresentaram durante a viagem uma disposição física imensurável aos olhos comuns. Saindo de Maturacá no dia 19 de setembro, viajaram em um barco pequeno (modelo voadeira), com motor $15 \mathrm{hp}$, até o fim do Rio lamirim, percurso que durou vinte e quatro horas de viagem, fazendo parada de algumas horas no xapono de Nazaré. Logo em seguida, viajaram de caminhoneta (Toyota Bandeirante) até a cidade de São Gabriel da Cachoeira, onde aproveitaram alguns dias para resolver questões da AYRCA e descansar. Depois, seguiram viagem de Barco expresso até a cidade de Manaus, trajeto de 24 horas ininterruptas, chegando no dia 26 de setembro. No dia 27, viajamos para cidade de Natal em voo comercial, fazendo uma conexão de seis horas na cidade do Rio de Janeiro. Chegando ao aeroporto, fizemos um translado até o hotel de cerca de uma hora e meia. Eu estava totalmente esgotado corporalmente, no entanto, assim que nos acomodamos no quarto do hotel, o pajé-hekura, de 76 anos de idade, se vira para mim e diz: "Professor, vamos passear?", ao que eu respondo: "Agora?" Ele acena afirmativamente. Lembro dos estudos de Schechner (2011, p. 60) e dou-me conta de que naquele momento estávamos nos pesquisando simetricamente, pois eu, exaurido, acompanhava o pajé-hekura, que encontrava-se viajando há muito mais tempo do que eu e apresentava uma disposição corporal inimaginável diante da situação. E a mesma disponibilidade manteve-se na viagem de volta até a partida de Manaus para São Gabriel da Cachoeira, ponto em que nos despedimos. A mesma disposição corporal da viagem, percebi nas sessões de xamanismo (hekuramou) nos xaponos da região de Maturacá e nas atividades de caça que eu participei junto com os Yanonami. 
Figura 2: ABRACE/2017. Pajé-hekura Carlos Lopes e o presidente da AYRCA Marcos

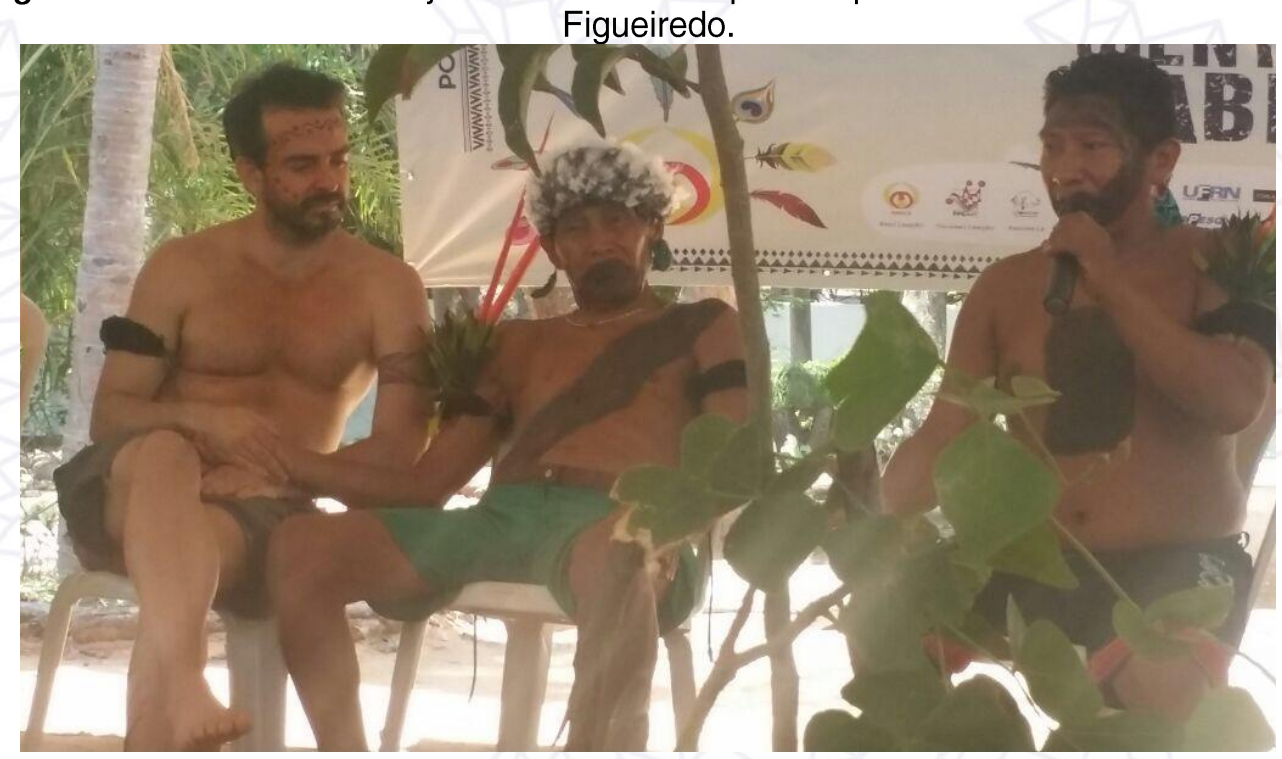

A publicação do livro $O$ Xamanismo Yanonami da Região de Maturacá/Yanonami të pë hekuramou Maturacá a xapono há (2018b), escrito em Língua Portuguesa e em Língua Yanonami, foi realizada com o apoio do Instituto Nacional de Ciência e Tecnologia Brasil Plural (INCT) e do grupo de pesquisa Maracá (CNPq/UFAM). O objetivo principal da publicação foi atender as escolas da região de Maturacá com um material pedagógico que abordasse a realidade do dia a dia dos alunos indígenas, neste caso, o recorte foi o ritual hekuramou. Vale salientar que, até o momento, nenhum livro ou material pedagógico foi elaborado levando como tema central o povo Yanonami da região de Maturacá e que a obra acima referida visa oferecer ao professor Yanonami uma ferramenta pedagógica que fomente a cultura da região, principalmente nas séries iniciais voltadas para o aprendizado da Língua Portuguesa e para o aprendizado da escrita em Yanonami.

O desejo de manter registrado o ritual e seus praticantes veio da liderança tradicional após a morte de importantes lideranças tradicionais, de quem não houve nenhum registro oficial de suas práticas ritualísticas tão respeitadas pelos pajés-hekuras ${ }^{2}$ e demais indígenas. Ou seja, agora eles

\footnotetext{
${ }^{2}$ A tradução para xamã na língua Yanomami falada pelos Yanonami é hekura, mesmo termo usado para espíritos. Assim, tomando a decisão de optar pelo termo da língua dos Yanonami, usarei "pajé-hekura" para xamã e "hekura-espírito" para denominar os espíritos. Do mesmo modo, utilizarei a palavra hekuramou ao invés de xamanismo.
} 
querem a fotografia e a escrita como forma de transmitirem a sua própria história aos novos Yanonami, além de terem recursos do napë que também os apresentem.

A construção da casa de apoio na frente sul de São Gabriel da Cachoeira teve como objetivo o suporte para os Yanonami e não indígenas que viajam da aldeia para a cidade. Predominantemente, essa viagem é feita para comercialização de artesanatos, compra de alimentos, compra de maquinário agrícolas e eletrônicos, além também de ser o momento em que aproveitam para receber valores de aposentadorias e bolsa família. Dessa forma, a casa de apoio passou a ser um ponto de descanso na viagem, a qual dependendo do barco utilizado, pode levar de um até cinco dias. A parceria para a construção da casa de apoio levou ainda em consideração o translado de indígenas de outras etnias que utilizam o mesmo acesso à região e, também, os não indígenas, como transportadores, pesquisadores, agentes de saúde, entre outros, que passam pelo local quando se deslocam para região do Brasil chamada de Cabeça do Cachorro.

Figura 3: Processo da construção da casa de apoio Yanonami na Frente Sul de São Gabriel da Cachoeira (AM).

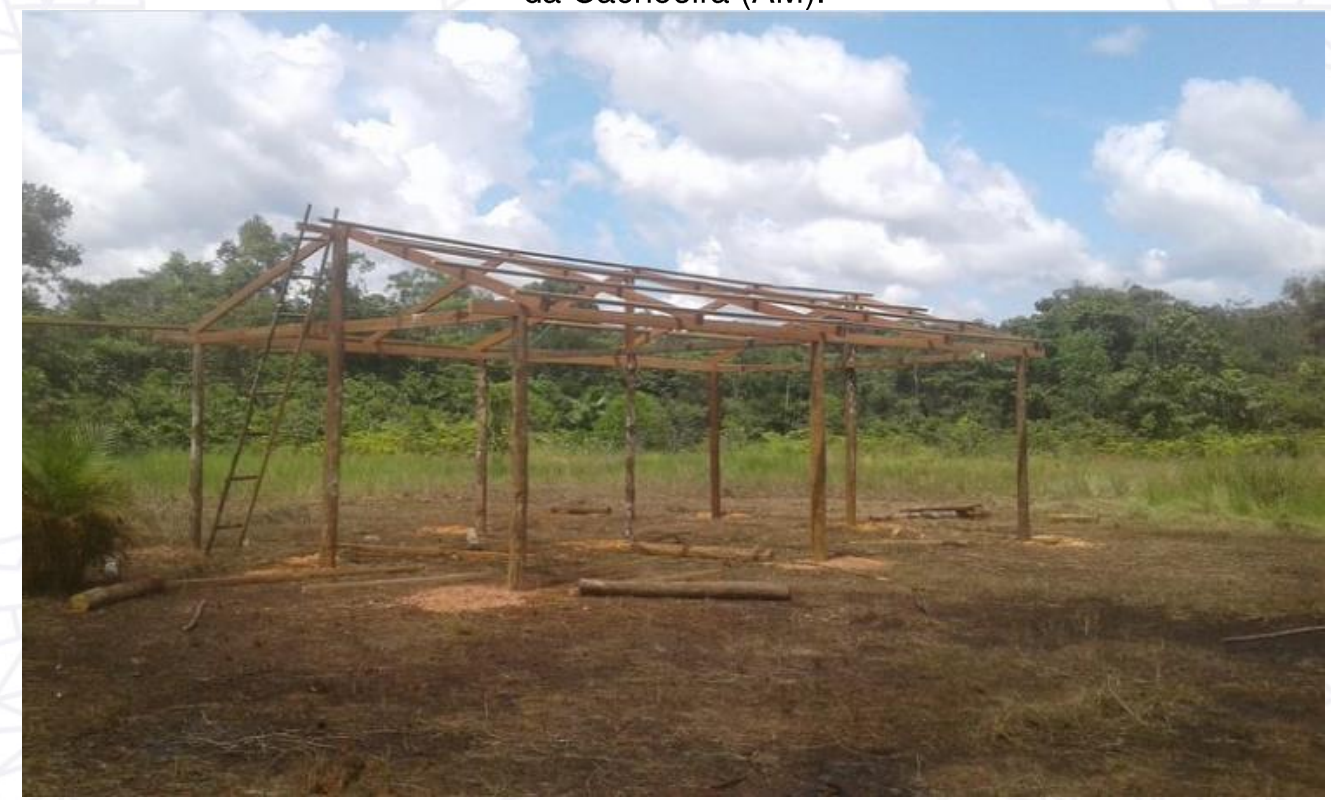

Fonte: Acervo do autor.

No contexto de pandemia do Covid-19, iniciada na cidade de Manaus em meados do mês de março de 2020, várias ações foram realizadas tendo 
como objetivo o combate ao contágio em povos indígenas. Nesse contexto, foi criada a rede de pesquisadores e apoiadores dos povos Yanomami e Ye'kwana, a fim de mapear o contágio no povo Yanomami com a Covid-19 e realizar ações que combatessem a proliferação do vírus. Entre as ações realizadas pelo grupo, destaca-se o documento Nota Técnica para Contribuir ao Combate da Covid-19 na Terra Indígena Yanomami (2020).

Essa nota técnica abordou assuntos como: casos confirmados, casos suspeitos, estratégias indígenas frente à pandemia, grave cenário epidemiológico e precarização do atendimento à saúde na TIY, o combate à epidemia da COVID-19 na TIY e recomendações. Neste trabalho, a presença como alguém que atua na região de Maturacá fez-se necessária para a contribuição com dados e informações da região.

Por conseguinte, retomo as palavras do Cacique Antônio Lopes em destaque na abertura deste subtópico, elas foram feitas durante uma sessão de hekuramou no xapono Maturacá, durante a minha primeira imersão junto ao povo Yanonami ainda em 2015: "Não foi você que veio até nós, foram os espíritos que trouxeram você para ajudar o povo Yanonami". Ou seja, enquanto eu, enrijecido com minhas ferramentas bibliográficas, pensava que estava fazendo a minha pesquisa mantendo o distanciamento racional, na verdade, o cacique, juntamente com os pajés-hekuras e os hekura-espíritos, já sabia e planejava o nosso encontro muito antes mesmo de nos conhecermos pessoalmente. Como aponta FAVRET-SAADA em texto traduzido por Siqueira (2005, p. 158) "Aceitar ser afetado supõe, todavia, que se assume o risco de ver seu projeto de conhecimento se desfazer.

No exercício da tríade corpo-cultura-aldeia/cidade, vale destacar o afeto construído em minhas participações nos rituais nas aldeias da região de Maturacá. A relação afetuosa neles nasce quando a armadura da metodologia científica foi se tornando obsoleta diante das situações vivenciadas junto aos Yanonami. Aos poucos, percebi que os problemas levantados no projeto de pesquisa já estavam respondidos. A carga pesada construída no planejamento inicial da pesquisa havia se aliviado e, assim, diante de um relaxamento, deixei-me afetar pelos rituais de que participava, na caça, pesca, colheita de frutas no mato e nos rituais, todas concomitante ao aprimoramento 
com a língua yanomami, assim, essas vivências foram me conduzindo para o entendimento sobre os desejos de que os Yanonami queriam a minha presença junto a eles - kõkamõu (GONÇALVES, 2019).

Figura 4: À esquerda, Cacique Antônio Lopes, e à direita, o branco Luiz Davi.

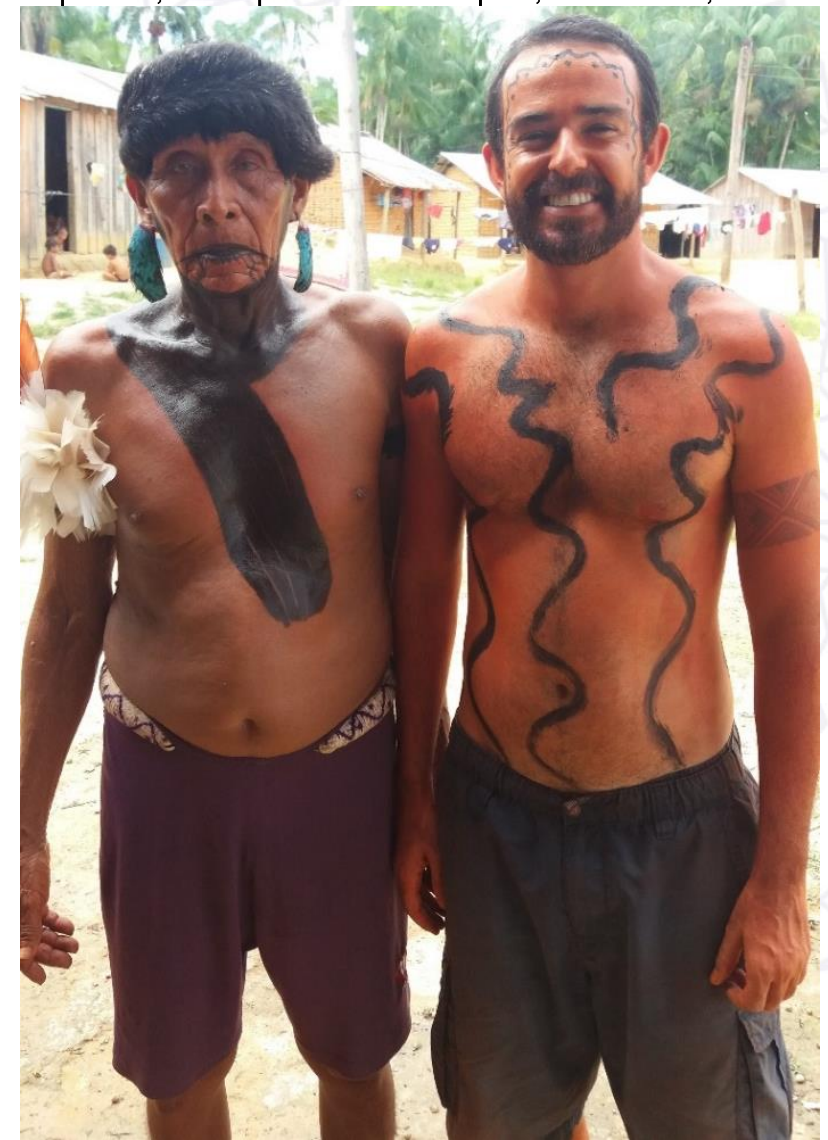

Fonte: Acervo do autor.

As relações em Maturacá, em minha casa na cidade de Manaus e nos eventos, estabeleceram não apenas uma relação afetuosa e de confiança, mas também uma relação de corpo. Toda essa afetação e esse envolvimento foram importantes para a minha compreensão das noções de corpo Yanonami e das orientações cosmológicas no processo de sentir, escutar e receber tudo o que nos acontecia. Houve entre nós, nas danças, nos rituais nos xaponos, nas atividades em minha casa e nas demandas dos eventos, uma afetação entre o meu corpo e o corpo deles, fazendo com que eles abrissem caminhos para que eu compreendesse a corporalidade Yanonami com mais profundidade e, ao mesmo tempo, levando-os a entender as minhas 
percepções de corpo - sendo assim uma escuta de todos os corpos. Portanto, o conhecimento encorporado, como Schechner destaca:

\begin{abstract}
Mestres do transe - xamãs, performers de Candomblé e outros performers tradicionais, assim como alguns artistas - treinaram seu cérebro-corpo (bodybrain) usando métodos tradicionais. É chegada a hora de investigar e caracterizar esses métodos - de tratá-los como conhecimentos encorporados. A antiquada oposição entre o pensamento e a ação "racionais" e "instintivos" precisa ser descartada em favor de estudos holísticos que tratem mestres da performance não como "objetos de estudo", mas como parceiros de pesquisa (SCHECHNER, 2011, p. 60).
\end{abstract}

No tocante à concepção, pensar o que é corpo levando em consideração a afetação simétrica estabelecida com os Yanonami é assumir as vozes da experiência estabelecidas pela metodologia kõkamõu, reconhecendo o risco de ver seu projeto de conhecimento se desfazer, como citado anteriormente por Jeanne Favret-Saada (1990). Entretanto, reconhecer o desmantelamento do próprio projeto de conhecimento não é deixar e/ou negar os planejamentos, os estudos, a própria construção social, tampouco a preparação realizada para pesquisa e/ou trabalho. Na verdade, reconhecer é aceitar as verdades diferentes do planejado e até do imaginado, deixando-se conduzir simetricamente também nas alteridades corporais.

\title{
Fechando as cortinas - considerações em processo
}

Portanto, o local da experiência na tríade corpo-cultura-aldeia/cidade é estabelecido diante da afetação construída, desenvolvida e administrada durante o estado kõkamõu, e cada realidade apresentará seu alcance nas negociações, na criatividade e assim a dinâmica da interação humana, na responsabilidade afetiva e principalmente na manutenção da afetação diante das interpelações normais de qualquer relação afetiva. Nos dizeres da pesquisadora Jean Langdon: "Atendendo as questões contemporâneas que tratam da experiência de estar no mundo" (LANGDON, 2009, p. 176).

Nesse sentido, percebemos que a realização do Suwê pë Kõkamõu, a participação na ABRACE e a elaboração do livro, são posicionamentos políticos de etnicidade e afirmação da cultura tradicional por parte das 
Associações indígenas de Maturacá, AYRCA e AMY-Kumirãyõma, das lideranças tradicionais e do povo Yanonami desta região. Portanto, a metodologia kõkamõu é também um jogo político na manutenção e luta pelos direitos dos povos tradicionais.

Sobretudo, o objetivo central é refletir sobre como, nos tempos atuais, podemos desenvolver uma relação simétrica entre artista e povos tradicionais levando em consideração as armadilhas interculturais. Sem sombra de dúvida, não existe uma receita pronta para essa questão, algo que servirá para todos os projetos. Entretanto, caminhar simetricamente é estabelecer um vínculo de interesses construídos concomitantes em ações no "mundo" do branco e no "mundo" dos povos tradicionais, levando em consideração os afetos frutos dos movimentos que a vida traz para qualquer ser humano. Napë yahopiha yanonami te yare, Yanonami te yahipiha napë a yare, na língua yanonami (tem Yanonami na casa do branco, tem branco na casa do Yanonami). Por fim, a regra é não ter regra, e sim deixar os afetos fluírem kõkamõu.

\section{Referências bibliográficas}

ICLE, Gilberto; Haas Marta. Gesto decolonial como pedagogia: práticas teatrais no Brasil e no Peru. In: Revista Urdimento, Florianópolis, v.3, n.36, p. 96-115, nov/dez 2019

GONÇALVES, Luiz Davi Vieira. Estudos Étnicos nas Artes da Cena: a metodologia Kõkamõu como perspectiva simétrica para o processo de pesquisa e criação em arte. Revista Arte da Cena, v. 4, p. 18-41, 2018 .

GONÇALVES, Luiz Davi Vieira. Yanonami të pë hekuramou maturacá a xapono há - O xamanismo Yanonami da região de Maturacá. Goiânia: Editora Espaço Acadêmico, 2018b.

GONÇALVES, Luiz Davi Vieira. O(s) corpo(s) Kõkamõu: a performatividade do pajé-hekura Yanonami da região de Maturacá. 2019. Tese (Doutorado em Antropologia Social) - Universidade Federal do Amazonas, Manaus, 2019. LANGDON, E. J. Performance e sua diversidade como Paradigma Analítico: a contribuição da abordagem de Bauman e Briggs. In: Revista de antropologia llha. v. 8, n. 1 e 2, p. 163-183, jul./dez. 2009. 
Corpos Kõkamõu: uma relação simétrica entre indígena e não indígena na tríade corpocultura-aldeia/cidade

PAVIS, Patrice. A encenação contemporânea: origens, tendências, perspectivas. São Paulo: Perspectiva, 2010.

RAMOS, A. R. et al. Nota Técnica para contribuir ao combate da Covid-19 na terra indígena Yanomami. Disponível em: https://www.facebook.com/RedePr\%C3\%B3-Yanomami-e-Yekwana-105086877893044. Acesso em: 05 de Maio. 2020

SCHECHNER, Richard. Pontos de contato entre o pensamento antropológico e teatral. In: Cadernos de Campo, São Paulo, n. 20, p. 213-336, 2011. SIQUEIRA, P. "Ser afetado", de Jeanne Favret-Saada. Cadernos de Campo (São Paulo 1991), v. 13, n. 13, p. 155-161, 30 mar. 2005. 